\title{
RESOLVING CONTRADICTIONS IN ENDORSER EFFECTIVENESS: AN EMPIRICAL TEST FOR A NEW FRAMEWORK
}

\author{
Kazuki Kubota, Keio University, Japan
}

\begin{abstract}
Identifying the most effective type of advertising endorsers has been one of the main research topics on advertising research. For example, Friedman and Friedman (1979) found that celebrity endorsers are more effective than expert or typicalconsumer endorsers in sustaining recall of both advertisement and brand name. This finding leads us to conclude that celebrity endorsers are superior to non-celebrity endorsers.
\end{abstract}

However, several researchers have provided empirical evidence suggesting that celebrity endorsers are less effective. Tom et al. (1992) found that created spokespersons are more effective than celebrity endorsers and claimed "originally created material, ..., is more effective in creating memorability than the adoption of popular material" (p. 50). Recently, Pashupati (2009) claimed "brands using spokescharacters perform better than average in recall" (p. 373).

The objective of this research, therefore, is to resolve this apparent contradiction. In order to do so, a new framework for classifying advertising endorsers was introduced. The framework consists of two dichotomies, i.e., "original/non-original" and "fictional/non-fictional". The "original/non-original" dichotomy implies whether the advertising endorser originally achieves his/her public recognition through the advertising in question. The "fictional/non-fictional" dichotomy, on the other hand, implies whether personalities of the advertising endorser are fictionally created through the advertising.

Based on the framework, the features of advertising endorsers derived from previous research were examined and classified. Following hypotheses were proposed: (1) Non-original endorsers are more effective than original endorsers. (2) Fictional endorsers are more effective than non-fictional endorsers.

Those hypotheses were empirically tested with a consumer dataset. The results supported the hypotheses and thus, indicated that the contradictory findings in previous research could be resolved using the new framework proposed in this research.

References available upon request. 